\title{
Método de ensino para projetos de urbanismo mais sustentáveis: resultados da integração horizontal das disciplinas de projeto de urbanismo, paisagismo, infraestrutura e conforto térmico da FAU-UnB
}

\author{
ANDRADE, Liza M. S. \\ LIRA, Flaviana \\ RIBAS, Otto T. \\ SANT'ANA, Daniel' \\ SILVA, Caio F. \\ MEDEIROS, José M.
}

${ }^{1}$ Universidade de Brasília, Brasília, Brasil. arq.santana@gmail.com

\section{Resumo}

O ensino de arquitetura e urbanismo caracteriza-se pela sua interface com várias disciplinas a partir da compreensão dos fenômenos do espaço e da cidade. A ciência urbana requer estudos que minimizem os impactos ao meio ambiente e ao mesmo tempo deve atender às expectativas sociais. Neste contexto, um bom projeto urbanístico deve incorporar os elementos ambientais no seu processo de projetação como, por exemplo, a interface solo-vegetação-atmosfera, fundamental para o balanço de energia e no fluxo de volumes de água na bacia hidrográfica bem como para aplicação de estratégias próprias do microclima local. $\mathrm{O}$ artigo defende que as disciplinas de projeto de urbanismo nas universidades adotem metodologias de processo de projeto que possibilitem a integração de conhecimentos com disciplinas horizontais que possam ser aplicados nos projetos desenvolvidos nos ateliês. Este trabalho tem como objetivo demonstrar alguns resultados da metodologia aplicada aos projetos urbanísticos desenvolvidos por estudantes do 40 semestre da FAU/UNB com a integração transversal das disciplinas de Projeto de Urbanismo 1, Conforto térmico, Infraestrutura e Projeto de Paisagismo 1 para a Expansão da cidade do Paranoá no DF, uma comunidade de renda mais baixa. Utilizou-se como método de aplicação ao processo de projeto aquele das Dimensões Morfológicas do Processo de Urbanização (DIMPU) que contemplam os aspectos bioclimáticos, econômicos, funcionais, sociológicos, topoceptivos e expressivo-simbólicos paralelamente aos Princípios de Sustentabilidade Ambiental (Andrade, 2008) e aos princípios da gestão ecológica do ciclo da água no meio urbano. Os três projetos que alcançaram melhores desempenhos tentaram equilibrar as questões de densidade com desenhos e técnicas de infraestrutura verde e bioclimáticas.

Palavras-Chave: ensino de arquitetura e urbanismo, projeto de urbanismo sustentável, conforto térmico, infraestrutura, projeto de paisagismo.

\begin{abstract}
The teaching of architecture and urbanism is characterized by its interface with various subjects from the understanding of space and city phenomena. The urban science requires studies that minimize environmental impacts and at the same time must attend social expectations. In this context, a good urban project should incorporate environmental elements in the design process, for example, the interface soil-vegetation- atmosphere, fundamental to energy balance and water flow volumes in drainage basin as well as for application of strategies related to the local microclimate. The article argues that the disciplines of urban planning inside the universities should adopt methodologies of design process that enable the integration of knowledge with horizontal disciplines that could be applied in the projects developed in the ateliers. This paper aims to demonstrate some results of the methodology applied to urban projects developed by 4th semester students at UnB School of Architecture and Urbanism, with the transversal integration of the following disciplines: Urban Planning 1, Thermal Comfort, Infrastructure and Landscape Design 1. The study case was a low income community in the expansion of a satellite city called Paranoa in Federal District, Brasilia, Brazil. The methodology applied in the planning process is known as Morphologic Dimensions of Urbanization Process (DIMPU) that include bioclimatic, economic, functional, sociological, topoceptive and expressive-symbolic aspects, parallel to the Principles of Environmental Sustainability (Andrade, 2008) and the principles of ecological management of the water cycle in urban areas. The three projects that have achieved best performances attempted to balance questions of density by using drawings and green and bioclimatic infrastructure techniques.
\end{abstract}

Keywords: teaching of architecture and urbanism, sustainable urbanism planning, thermal comfort, infrastructure, landscape planning. 


\section{Introdução}

O planejamento urbano-ambiental requer posicionamentos teóricos e generalizações conceituais possíveis para promover a capacidade de articulação das escalas e correta compreensão da inserção das cidades na natureza, quanto às estratégias de uso e ocupação do solo, incluindo a discussão sobre morfologia urbana, clima urbano, ecologia, hidrologia, tipologias de parcelamento e edificações bem como ferramentas de análise e subsídios para formulação de projetos e políticas públicas. É necessário promover um avanço teórico no campo epistemológico do planejamento urbano-ambiental que possibilite pensar a cidade perante uma dimensão complexa multidimensional, sistêmica e holística, considerando os vários planos setoriais do território existentes em uma bacia hidrográfica e a incerteza das mudanças advindas das mudanças climáticas, da economia global, e da tecnologia de informação.

Segundo Holanda (2003), o espaço urbano é explicado como uma "variável" dependente de resultado de determinadas políticas, situações socioeconômicas, históricas-sociais, conflitos de classes, processos de poder, ideologias, em outras palavras é "resultante disso". Entretanto, - campo disciplinar da Arquitetura e do Urbanismo está inserido no campo da ciência social aplicada, mas ao mesmo tempo, que ele procura atender às expectativas sociais, tem reflexos na sociedade, causa impacto no meio físico e nas pessoas. Neste caso, segundo Holanda e Kohlsdorf (1995) e Holanda (2003), deveria ser considerado como uma "variável independente" que causa impacto no meio ambiente, na flora, na fauna, nos ecossistemas, nos recursos hídricos, no solo, etc. e, ao mesmo tempo deve atender as expectativas sociais para um bom desempenho quanto aos aspectos funcionais, bioclimáticos, econômicos, sociológicos, de identidade e orientabilidade, afetivos, simbólicos e estéticos bem como éticos e ecológicos.

Portanto, é necessário o desenvolvimento de estudos que passe por uma investigação do espaço urbano como uma "disciplina acadêmica". Segundo Kohlsdorf (1985 p.20), "uma disciplina só se estabelece quando explicitada tanto sua componente profissionalizante", com o estabelecimento de regras de ação, quanto a sua componente "especulativa", com o procedimento ao conhecimento de seu objeto.

Na visão de Campomori (2004), o que caracteriza o ensino de arquitetura e urbanismo é a sua interface com várias disciplinas e não uma disciplina. A constante busca de uma ampliação da compreensão do que sejam os fenômenos do espaço e da cidade, certamente contribuiu para aproximar o urbanismo de disciplinas de outras áreas do conhecimento tais como, economia, sociologia, antropologia, direito, administração, geografia, ecologia, entre outras. Assim, mostrou-se possível a complexificação do conhecimento e ao mesmo tempo se colocou efetivamente como uma proposta. A este fato, deve-se somar a particularidade da regulamentação profissional da área no Brasil, qual seja a habilitação única em Arquitetura, Urbanismo e Paisagismo ou mesmo o saber fazer do desenhista urbano que faz a ponte entre as disciplinas e seus representantes das áreas de arquitetura, o urbanismo, o paisagismo e planejamento urbano (CAMPOMORI, 2004).

Entretanto, diante das incertezas ambientais e dos riscos ambientais que envolvem as comunidades carentes deve ainda incorporar os elementos das áreas de sociologia, ecologia, geologia, hidrologia e climatologia. A interface solo- vegetação-atmosfera exerce um papel fundamental no balanço de energia e no fluxo de volumes de água na bacia hidrográfica bem como no microclima local. À medida que as cidades crescem esse equilíbrio é alterado. Neste sentido, torna-se importante nas disciplinas de projeto de urbanismo adotar metodologias que possibilitem ou favoreçam uma integração com as disciplinas horizontais teóricas e tecnológicas como infraestrutura ecológica, conforto, paisagismo, entre outras, para promover a aplicação dos atributos morfológicos.

O método de processo de projetação da disciplina de Projeto de Urbanismo 1 da FAU/ UnB baseia-se na metodologia de projetação arquitetônica fundamentada na taxonomia por resposta dimensional a partir da pesquisa Dimensões Morfológicas do Processo de Urbanização - DIMPU - (Holanda, F.; Kohlsdorf, G.; Kohlsdorf, M.E. e Villas Boas, M., Brasília: FAU-UnB / FINEP / CNPq, 1985 - 1994) ${ }^{1}$ e no método dos Princípios de Sustentabilidade Ambiental (Andrade, 2008) e na gestão ecológica do ciclo da água no meio urbano. As dimensões contemplam os aspectos bioclimáticos, econômicos, funcionais, sociológicos,

$1 \quad$ Implantada pelos coordenadores Gunter e Maria Elaine Kohlsdorf e posterior mente assegurada pela coordenadora Juliana Garrocho e professores do núcleo docente estruturante. Ver site da metodologia no grupo de pesquisa da FAU-UNB. http://www.unb. br/fau/dimpu/index.html; http://www.unb.br/fau/cidade_arquitetura/ 
topoceptivos e expressivo-simbólicos Assim, os aspectos teóricos e metodológicos adotados favoreceram a integração horizontal com as outras disciplinas do quarto semestre, Infraestrutura, Conforto Térmico e Projeto de Paisagismo 1.

\section{Objetivo}

Este trabalho tem como objetivo demonstrar os resultados dos projetos urbanísticos mais sustentáveis para a Expansão do Paranoá, desenvolvidos no 40 semestre do curso noturno da Faculdade de Arquitetura e Urbanismo da UnB, e que resultaram de um processo de integração transversal das disciplinas de Projeto de Urbanismo 1, Infraestrutura, Conforto Térmico Ambiental 1 e Projeto de Paisagismo 1.

\section{Método}

A exposição do método projetual adotado, bem como as contribuições de cada umadas disciplinas e os resultados alcançados serão apresentados neste artigo em quatro partes assim intituladas: (1) a metodologia de processo da disciplina de Projeto de Urbanismo 1- PU1; (2) as contribuições transversais da disciplina de Infraestrutura; (3) as contribuições transversais da disciplina de Conforto Térmico Ambiental; (4) as contribuições transversais da disciplina de Projeto de Paisagismo 1.

\subsection{A metodologia de processo de Proje- to de Urbanismo 1}

A teoria de projeto adotada para o processo de projetação da disciplina de Projeto de Urbanismo 1 da FAU/UnB baseia-se na metodologia de projetação arquitetônica fundamentada na taxonomia por resposta dimensional a partir da pesquisa Dimensões Morfológicas do Processo de Urbanização (Grupo DIMPU/UNB). Consiste na avaliação do espaço arquitetônico em relação a cada expectativa social. Desenvolve-se, portanto, várias avaliações de um mesmo lugar, cada uma relacionada à determinada dimensão. Entendendo-se por dimensão "todo plano, grau ou direção no qual se possa efetuar uma investigação ou realizar uma ação"2.

Holanda e Kohlsdorf (1996) propõem entender arquitetura como qualquer espaço socialmente utilizado e, portanto, como situação relacional e

2 ABBAgnANO, N. Dicionário de Filosofia. São Paulo: Ed. Mestre Jou, 1982:260 dimensional. A qualidade de um mesmo espaço arquitetônico pode variar conforme cada expectativa/dimensão considerada; seu juízo global é uma ponderação entre avaliações parciais, pois as expectativas/dimensões recebem priorizações diferentes para cada indivíduo ou grupo social considerado. A classificação de expectativas sociais gera taxonomia dos lugares que são as dimensões com várias descrições de um mesmo lugar, segundo diferentes atributos (categorias e elementos analíticos).

A teoria agrupa seis dimensões equânimes: funcionais, bioclimáticas (conforto térmico, acústico, luminoso e qualidade do ar), econômicas (infraestrutura urbana), expressivosimbólicas, sociológicas (facilidade de encontros não programados no espaço público) e topoceptivas (orientação e identificação). Não existem, em princípio, diferenças de valor entre elas. Considerar uma ou outra mais importante é questão dependente de pessoas, grupos e contextos culturais. A metodologia é divida em três movimentos recorrentes, análise da situação existente, avaliação de desempenho quanto às expectativas sociais, às dimensões morfológicas e propostas de programa de necessidades em todas as dimensões analisadas.

Além do vínculo entre pessoas e espaços da cidade, registram-se relações mais abrangentes em seu cotidiano, porém envolvendo necessariamente as articulações que se estabelecem entre os indivíduos e os lugares onde estão. Isto porque, em todos os tempos e situações onde haja processo social, sempre existem relações entre pessoas, de pessoas com o meio ambiente e de pessoas com o mundo simbólico. Assim, desenvolveram-se áreas de conhecimento para tratar de cada uma dessas "macrodimensões": as primeiras são objeto do campo da ética; as segundas, da ecologia e, as terceiras, do campo da estética.

A dimensão ecológica aplicada à arquitetura estuda como a arquitetura realiza conceitos de natureza e conceitos do homem enquanto natureza, nas suas relações com a natureza, nas suas relações de maneira geral. Os valores ecológicos aplicados informam a maneira pela quais as características do sítio natural são incorporadas ao projeto do edifício ou de lugares como o relevo, o clima, os processos hidrológicos, os recursos regionais (disponibilidade e escassez), a cultura local como também a classe social de seu usuário e a gestão da construção.

Na macrodimensão ecológica da DIMPU foram introduzidos os princípios de sustentabilidade 
estudados por Andrade (2005) que consiste em traduzir os princípios baseados em Dauncey e Peck (2002) em estratégias e técnicas para o processo de desenho do espaço urbano. É uma tentativa de incluir a visão sistêmica no processo de planejamento para integrar os atributos das Agendas Verde e Marrom. Tais princípios são: proteção ecológica (biodiversidade), adensamento urbano em área centrais, revitalização urbana de áreas degradadas, implantação de centros de bairro e desenvolvimento da economia local, implementação de transporte sustentável e moradias economicamente viáveis, comunidades com sentido de vizinhança, tratamento de esgoto alternativo, drenagem natural, gestão integrada da água, energias alternativas e, finalmente, as políticas baseadas nos 3R's (reduzir, reusar e reciclar).

Segundo o Manual da UNESCO (2008), sobre o Ciclo da Água no Meio Urbano, a arquitetura urbana e o estilo de vida das pessoas são dois aspectos que possuem impactos diretos na gestão dos recursos hídricos nas áreas urbanas. Segundo Andrade e Ribas (2012), a arquitetura urbana compreende, dentre outras coisas, a densidade da população e edificações, sistemas de coleta de água da chuva, material usado na construção, e sistema de coleta de águas residuais Já o estilo de vida das pessoas afeta o ciclo hidrológico por meio de mudanças nas demandas domésticas de água, sendo o uso per capita doméstico e o uso em áreas públicas (parques e áreas verdes) as principais características que definem este estilo de vida.

De acordo com Gauzin-Müller (2002), a gestão ecológica do ciclo da água no meio urbano consiste em: (1) proteger o lençol freático e as águas superficiais; (2) reduzir o consumo de água potável e garantir sua qualidade; (3) minimizar o volume de água residual para limitar os custos relacionados com seu tratamento, com - redimensionamento das redes existentes saturadas e, com a construção de novas estações de tratamento; (4) garantir um tratamento ecológico das águas residuais; (5) limitar a impermeabilização das superfícies para reduzir os riscos de inundações; (6) criar bacias de captação integradas com os espaços verdes que melhorem, simultaneamente, a qualidade do ar e o clima social.

Considerando a interface solo-vegetaçãoatmosfera determinante para melhorar o desempenho climático da área, bem como a manutenção do ciclo hidrológico da região da Bacia do Paranoá, entendeu-se como absolutamente coerente em termos pedagógicos uma abordagem holística do tema, o que foi concretizado pela integração transversal das disciplinas de Infraestrutura Urbana, Conforto Térmico e Projeto de Paisagismo 1 à disciplina de Projeto de Urbanismo 1, todas ministradas no quarto semestre da Faculdade de Arquitetura e Urbanismo da Universidade de Brasília.

\subsection{As contribuições transversais da dis- ciplina de Infraestrutura Urbana}

A disciplina de Infraestrutura Urbana foi desenvolvida para apresentar não apenas sistemas convencionais de abastecimento de água, esgotamento sanitário, drenagem urbana e serviços de eletricidade, mas também de infraestrutura urbana verde, visando demonstrar aos alunos sistemas alternativos voltados à gestão sustentável de água e energia. A metodologia de ensino da disciplina utilizou conceitos da abordagem triangular de (i) leitura, (ii) contextualização, e (iii) projeto.

Como ponto de partida, os alunos realizaram a leitura das instalações urbanas na Região Administrativa Paranoá, identificando suas redes de infraestrutura convencionais existentes, para que, em seguida, fosse contextualizado o desempenho dos diferentes sistemas em termos ambientais.

Apesar de Brasília ter sido inicialmente uma cidade planejada com muitas áreas verdes, já foram constatados assoreamento dos corpos d'água e ilhas de calor. Portanto, para melhorar o desempenho do ciclo hidrológico da região bem como o desempenho climático, é necessário que o desenho urbano incorpore o conhecimento de novas tecnologias de infraestrutura verde integradas ao contexto social, econômico, cultural e político. Após o levantamento de uma série de problemas relacionados à infraestrutura convencional, os estudantes identificaram diferentes soluções voltadas à redução do impacto ambiental através de diferentes tecnologias e sistemas voltados à infraestrutura verde e à gestão ecológica do ciclo da água no meio urbano: lagoas de retenção, canais de infiltração, jardins de chuva, tratamento e reuso de água, armazenamento de água da chuva.

Atuando em parceria com a disciplina de Projeto de Urbanismo 1 dentro da Dimensão Econômica da DIMPU, os alunos aplicaram esses conceitos em uma atividade interdisciplinar voltada ao desenvolvimento de um projeto de infraestrutura urbana verde integrado ao seu projeto de urbanismo sustentável em uma área de expansão do Paranoá. 
Os atributos trabalhados na Dimensão Econômica da disciplina de PU 1 que foram fortalecidos na disciplina de Infraestrutura foram: custos provenientes da infraestrutura urbana (custos gerais dos sistemas, rede entradas e saídas - de onde vem o recurso natural e para onde vai o resíduo, custos a partir de características morfológicas) e custos devidos à superestrutura (custos a partir de características morfológicas, custos provenientes da incidência de áreas livres públicas e privadas, custos do edifício)

\subsection{As contribuições transversais da dis- ciplina de Conforto Térmico Ambiental}

A disciplina de Conforto Térmico Ambiental 1 introduz a cadeia de conforto ambiental no currículo do curso de Arquitetura e Urbanismo da Universidade de Brasília. Neste sentido, apresenta-se como ementa uma ampla introdução ao tema de conforto, às premissas do bioclimatismo e leitura dos recursos ambientais incorporadas ao projeto. Especialmente neste semestre, focou-se o projeto de urbanismo como objeto de estudo. A dinâmica do bioclimatismo requer uma estreita relação entre o fazer urbano e a compreensão do meio ambiente. Na prática, reconhece-se um distanciamento entre a produção dos espaços construídos e urbanizados e a prática do bioclimatismo nos projetos urbanos. Este afastamento tem reflexo no empobrecimento cultural da população. Vê-se que o processo de construção da cidade, cada vez menos envolvida com o seu contexto ambiental, prejudicam o desenvolvimento sustentável e ampliam os impactos ambientais gerados no processo de urbanização e na produção do espaço construído.

Na visão de Romero (2011), os fatores climáticos locais como a topografia, a vegetação e o revestimento do solo são os verdadeiros responsáveis pelas alterações do desempenho climático na pequena escala urbana, conformando o microclima. Segundo dados do Instituto Nacional de Meteorologia (INMET) no caso de Brasília, a temperatura média anual aumentou em 1,20C nos últimos 20 anos, passou de 20,2oC em 1992 para 21,4oC em 2012. Assim, é necessário fazer uma leitura acertada do meio ambiente, considerando o espaço construído e o espaço natural, para a gestão do território mais equilibrada à permanência do homem com menos impactos e, dita, mais sustentável.

Nos estudos realizados por Romero (2011) nas superquadras foi comprovado o aparecimento da ilha de calor como fenômeno noturno, quando
- calor armazenado durante o dia pelas construções é dissipado, elevando-se a temperatura no período noturno. A correlação linear entre as áreas verdes (árvores de médio porte) e a temperatura foi negativa para os três horários analisados: 9, 15 e 21 horas. A existência de vegetação de copa densa no espaço aberto diminui a temperatura ambiente, quando fornece sombra bloqueando a radiação direta no piso.

Segundo Gouvêa (2002, p. 55), a presença de grama ou asfalto/cimentado em uma superfície causa diferenças significativas na temperatura ambiente de um espaço público aberto. Em Brasília, foram registradas diferenças de até $1,50 C$ nas medições de temperatura ambiental quando comparadas as temperaturas em locais com grama e com asfalto/cimentado, sendo a grama o material que provoca menos calor. Já nas medições de temperatura superficial na sombra, a diferença entre o asfalto e a grama é de até $120 \mathrm{C}$ e no sol, as diferenças diminuem para até $9,9 \circ C$, sendo a grama sempre o material com os menores valores de temperatura.

Neste sentido, os alunos da disciplina de Projeto de Urbanismo 1 com o método da DIMPU, aplicaram as técnicas de conforto térmico no projeto dentro da Dimensão Bioclimática que abrange o conforto ambiental (térmico, luminoso, acústico e qualidade do ar) aplicado ao desenho urbano. Os atributos trabalhados na disciplina de PU 1 que foram fortalecidos na disciplina de Conforto Térmico Ambiental foram: configuração do relevo do solo, densidade de ocupação, orientação solar e eólica, permeabilidade do solo, áreas aquíferas, vegetação, rugosidade, porosidade, materiais constituintes das superfícies, uso do solo além dos aspectos de geometria urbana como a relação $\mathrm{W} / \mathrm{H}$ que estava sendo proposta no projeto de urbanismo. Pode-se observar inicialmente que os alunos passam a reconhecer a importância das estratégias de conforto térmico quando são rapidamente aplicadas no projeto em questão. Compreendem que os recursos ambientais favoráveis ao projeto arquitetônico: ventilação e radiação, como fonte de luz e calor, além da umidade relativa do ar devem ser tratados, antes de tudo, como recursos urbanísticos, permitindo que o desenho urbano gerado seja capaz de proporcionar um bom desempenho microclimático para o projeto urbanístico em questão.

Podem ser listados alguns pontos positivos da integração transversal: (1) os estudantes afinam o senso crítico para lidar com diferentes dimensões nas decisões projetuais, não privilegiando o conforto térmico, por exemplo, 
em detrimento da funcionalidade; (2) a disciplina de conforto térmico ambiental mantém um forte elo com a prática projetual, vantagem e objetivo buscado pela cadeia ambiental do departamento de tecnologia da FAU; (3) e, ainda, os estudantes cristalizam os conhecimentos de conforto térmico na experiência de projeto, mais duradoura e palpável.

\subsection{As contribuições transversais da dis- ciplina de Projeto de Paisagismo 1}

A disciplina de Projeto de Paisagismo 1 introduz a teoria de projeto adotada tradicionalmente no campo do paisagismo e baseia-se no estudo dos sistemas de espaços livres. Para a realização da integração entre as disciplinas, com área de trabalho na Expansão da Cidade do Paranoá, focalizou-se a atenção na "macrodimensão ecológica" da metodologia da DIMPU e nos princípios de sustentabilidade ambiental.

Foi estudada uma nova linha de trabalho na arquitetura da paisagem que, segundo Medeiros (2008, p. 08), "é baseada em uma compreensão mais ecológica do mundo em que o homem e seu modus operandi está mais inserido no contexto natural. Nessa perspectiva utilizam-se temas e repertórios relacionados à dinâmica natural com vista à preservação do meio ambiente". Nesse contexto, o paisagismo ecológico busca a preservação dos ecossistemas e da biodiversidade local por meio da conservação de aspectos e dinâmicas imprescindíveis para a troca de material gênico e da preservação de habitats e de nichos ecológicos, o que muitas vezes parece estar contra os interesses tradicionais do planejamento urbano, comprometidos com o desenvolvimento econômico e social.

A realidade social da cidade do Paranoá, também inspirou a introdução da temática da agricultura urbana e de seu papel na renovação urbana. A agricultura urbana pode ser praticada e estimulada facilmente nas áreas centrais das cidades, podendo ser vista como uma nova perspectiva para projetos urbanos, pois além da produção alimentícia, é capaz de fornecer aos habitantes uma melhoria estética e ambiental de seus bairros (Medeiros, 2012, p.03).

\section{Análise de resultados dos projetos}

Apesar de Brasília ter nascido de um plano urbanístico rigoroso baseado no urbanismo moderno, o uso e a ocupação do solo do Distrito Federal não ocorrem de forma planejada.
Segundo Fonseca e Braga Netto (2001, p.259), em grande parte os projetos urbanísticos das expansões das cidades foram implantados desconectados do planejamento territorial. Surgiram por meio de pressões de demandas por habitação, forçando, constantemente, a expansão dos espaços residenciais. Isso que dizer que a produção de parcelamentos voltados para a especulação imobiliária ou a oferta de lotes para população de baixa renda, bem como as ocupações irregulares e invasões, comuns em Brasília, são distantes da regulação urbanística e ambiental, desconectados do conjunto de políticas públicas.

Segundo relatório da UNESCO de 2003 sobre a vegetação e a ocupação do solo no DF entre 1954 e 2001, o Distrito Federal perdeu cerca de $67 \%$ da cobertura da vegetação natural no cerrado (1954 - 2001), com destaque para 47,2\% da perda de matas de galeria. Essa fisionomia é um filtro natural que protege as nascentes e os leitos dos cursos d'água, os quais já têm naturalmente problemas de vazões. Neste sentido, a oferta hídrica do Distrito Federal pode ficar comprometida, uma vez que há uma tendência em aumentar o aporte de sedimentos e poluição para dentro dos cursos d'água.

A Bacia do Paranoá está situada na porção central do Distrito Federal, e concentra maior número de assentamento, de empregos e de infraestrutura, além de estar parcialmente inserida na APA do Lago Paranoá.Atualmente o Lago Paranoá sofre um sério processo de assoreamento, causado pelas ocupações urbanas e pelo sistema tradicional de drenagem urbana. Formado em 1959, ocupava cerca de $48 \mathrm{~km} 2$ e, hoje, está com aproximadamente $40 \mathrm{~km} 2$ de área. O Lago Paranoá permite o uso múltiplo de suas águas: práticas esportivas, navegabilidade, cenário paisagístico e benefícios ao microclima local, geração de energia, recepção de esgotos nas estações de tratamento, e nos próximos anos será fonte de captação de água para consumo. Em 2009, a ANA concedeu à Companhia de Saneamento Ambiental do Distrito Federal (CAESB) a outorga para captacão no Lago Paranoá para abastecimento humano.

Portanto, segundo a CAESB, o abastecimento de água da Expansão da Cidade do Paranoá só será viável se a captação for feita no Lago Paranoá. Este é o cerne da questão: como expandir a cidade sem causar mais impactos ao lago, e garantir sua sustentabilidade ambiental? Ver a localização da área nas figuras 1 e 2.

A preocupação com a capacidade de suporte do lago é um dos motivos pelos quais o Governo do 
Distrito Federal (GDF) teve que suspender a implantação da Expansão da Cidade do Paranoá. A oferta hídrica no Distrito Federal é limitante de crescimento e desenvolvimento do território, em função da baixa vazão dos cursos d’água. Por outro lado, o aumento constante do crescimento populacional na capital do país é uma pressão constante sobre a crescente demanda por água.

$\mathrm{Na}$ visão de Andrade e Ribas (2012), outra questão importante a ser considerada é a ausência de integração entre os planos do território que dificulta a implementação de ações que minimizem o processo de assoreamento e promovam a sustentabilidade do Lago Paranoá. Portanto, acredita-se que na escala do desenho urbano, os projetos urbanísticos mais sustentáveis podem contribuir para a conexão entre as diretrizes dos planos do território.

Figura 1: Foto área do Lago Paranoá - Expansão do Paranoá. Fonte Google Earth.

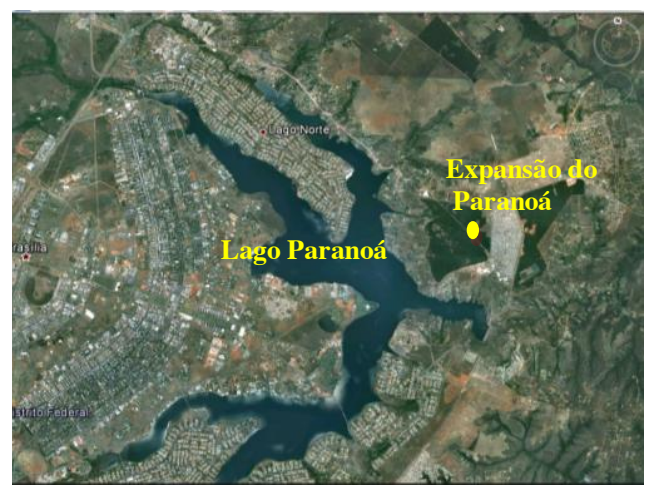

Figura 2: Foto área da Cidade do Paranoá; Expansão do Paranoá; Parque dos Pinheiros; Lago Paranoá. Fonte Google Earth.

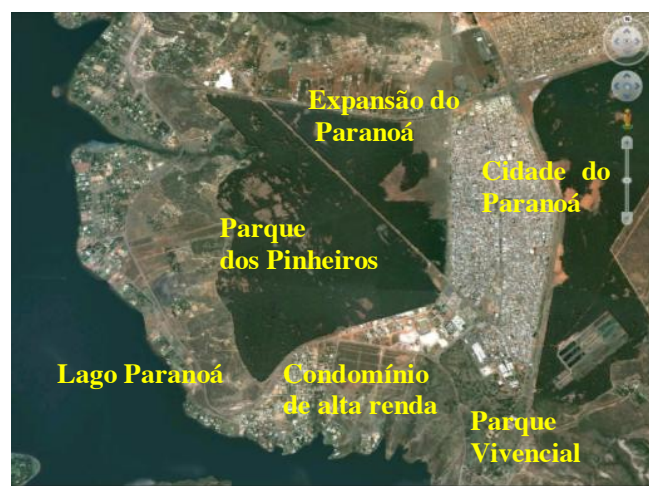

A cidade do Paranoá teve suas origens em meados de 1957, oficialmente criada em 1989 (Decreto no 12.027/89) para atender a uma população máxima de 60.000 habitantes, mas segundo a Regional Administrativa do Paranoá, a região já contém 63 mil habitantes e há um déficit habitacional hoje para atender 5.000 famílias. A Cidade do Paranoá já está no limite de sua capacidade de suprimento de água, bem como do recebimento de esgotos, drenagem pluvial, esgotamento viário, fornecimento de energia e aparelhos públicos. A justificativa do projeto de parcelamento do solo da Expansão do Paranoá é suprir o déficit demandado por famílias de baixa renda, residentes na própria cidade, na condição de inquilinos de fundo de lote. Inicialmente o projeto do GDF era implantar o novo parcelamento em uma área de 655,3935 hectares (considerando as fases 1, 2 e 3), com população estimada de 14.746 habitantes. Porém, esta área engloba o Parque dos Pinheiros, importante área verde para a contensão da drenagem das águas pluviais urbanas que escoam para o Lago Paranoá ambos inseridos na Área de Proteção Ambiental do Paranoá, na capital do Brasil.

De acordo com o Zoneamento Ambiental da APA do Paranoá, a cidade do Paranoá e a área de Expansão do Paranoá são consideradas Zona de Ocupação Especial e está na categoria de Subzona de Ocupação Especial do Paranoá - (ZOEP). Os objetivos dessa subzona, caracterizada por manchas de Cerrado degradadas e maciços de pinheiros da Proflora (em liquidação), é consolidar a área urbana da Cidade do Paranoá e a área da expansão do Paranoá, por meio de usos institucionais, residenciais, comerciais e industriais não poluentes. O "Parque do Pinheiros" está classificado como Zona de Vida Silvestre, na Subzona de Conservação da Vida Silvestre (ZPVS). Segundo o zoneamento, essa subzona é considerada menos restritiva e destina-se à conservação dos recursos ecológicos, genéticos e da integridade dos ecossistemas. Na zona são admitidos usos sustentáveis. Segundo o Plano Diretor de Ordenamento Territorial (PDOT, 2009) toda a área de estudo (incluindo a Cidade do Paranoá e seu entorno imediato dentro da bacia do Lago Paranoá) está na Zona Urbana de Uso controlado I. Essa zona é composta por áreas predominantemente habitacionais de muito baixa densidade demográfica, com enclaves de baixa, média e altas densidades. Permite ocupações de baixas densidades na área do Parque dos Pinheiros (15 a 50 hab/ha) e média densidade (entre 50 a 150 hab/ha) na Expansão do Paranoá. O uso urbano deve ser compatível com as restrições relativas à sensibilidade ambiental da área e à proximidade com o Conjunto Urbano Tombado ${ }^{3}$,

3 Com destaque para as seguintes diretrizes: (i) manter o uso predominantemente habitacional de baixa densidade demográfica; (ii) respeitar o plano de manejo ou zoneamento; (iii) proteger os recursos hídricos; (iv) adotar medidas de controle ambiental voltadas para áreas limítrofes às Unidades de Conservação; e, (v) preservar e valorizar os atributos urbanísticos e pai- 
Tabela 1: Análise dimensional da Cidade do Paranoá e Diretrizes para a Expansão

\begin{tabular}{|c|c|}
\hline Dimensões & Análise - Avaliação - Programação (síntese) \\
\hline Funcional & $\begin{array}{l}\text { O comércio é bem ativo e está localizado nas duas avenidas principais. Há alguns pequenos } \\
\text { comércios locais na área residencial. O parque vivencial (área da antiga Paranoá) se encontra } \\
\text { distante da cidade dificultando o acesso e a segurança. Recomenda-se aumentar a diversidade de } \\
\text { tipologias comerciais e residenciais, quadras, lotes e casa e blocos com áreas diferentes para } \\
\text { abranger diferentes classes e localizar as áreas livres públicas na área mais central da expansão. } \\
\text { Melhorar o acesso ao transporte público com vias mais acessíveis atravessando toda a expansão. }\end{array}$ \\
\hline Bioclimática & $\begin{array}{l}\text { A região da Cidade do Paranoá, quase em sua totalidade, é ocupada por superfícies edificadas e } \\
\text { coberta por pavimentação contribuindo para a formação de ilhas de calor. Os ventos } \\
\text { predominantes que vem do leste favorecem as primeiras macroparcelas, mas encontram alguns } \\
\text { obstáculos dificultando a porosidade e a rugosidade. Sugere-se para a expansão um traçado } \\
\text { urbano que dilua a alta densidade, intercalando áreas verdes entre as vias pavimentadas e } \\
\text { edificadas. Compreensão das fontes energéticas naturais (ventos dominantes e percurso aparente } \\
\text { do sol). }\end{array}$ \\
\hline Sociológica & $\begin{array}{l}\text { As vias mais integradas no sentido norte-sul recebem o comércio local e a maioria dos espaços } \\
\text { abertos convexos é pequena, tornando o espaço com tendência à urbanidade. Conectar as vias } \\
\text { existentes e gerar espaços com tendência à urbanidade (núcleos mais compactos), mesmo com } \\
\text { possibilidade de áreas verdes na parte central. }\end{array}$ \\
\hline $\begin{array}{l}\text { Topoceptiva e } \\
\text { Expressiva e Simbólica }\end{array}$ & $\begin{array}{l}\text { O traçado existente na cidade do Paranoá tem alguns elementos simbólicos como a igreja, a } \\
\text { administração a via de alta tensão e a torre de celular na praça principal. A via principal é } \\
\text { marcante pela quantidade de comércio e edifícios de } 4 \text { pavimentos, porém as placas de } \\
\text { propaganda tornam o ambiente caótico e monótono. Os efeitos perspectivos e topológicos não } \\
\text { são tão marcantes. Criar padrões espaciais que possibilitem o fortalecimento desses efeitos e } \\
\text { novos pontos focais e marcos visuais para melhorar a orientabilidade e identidade do lugar. }\end{array}$ \\
\hline Econômica & $\begin{array}{l}\text { O abastecimento de água e o tratamento de esgoto ocorrem em outra sub-bacia (Sistema Santa } \\
\text { Maria/Torto e Estação de tratamento da sub-bacia do Rio São Bartolomeu). O sistema de } \\
\text { drenagem é tradicional e sai carreando todas as impurezas contribuindo para o assoreamento do } \\
\text { lago. Sugere-se um sistema de tratamento de esgoto alternativo como o sistema "wetlands" com } \\
\text { leito cultivado para tratar o esgoto da expansão e um sistema de drenagem natural para melhorar } \\
\text { a manutenção do ciclo da água no meio urbano. }\end{array}$ \\
\hline
\end{tabular}

O Plano de Preservação do Conjunto Urbanístico de Brasília (PPCUB) de 2011, em processo de aprovação, determina que a área de Expansão do Paranoá siga as diretrizes propostas por Lúcio Costa, em 1987, para a Asa Nova Norte no documento Brasília Revisitada que incluía a fixação do Paranoá com quadras econômicas, conjuntos geminados (habitação popular), quadras pilotis e quatro pavimentos e lotes individuais.

\subsection{Análise, avaliação da cidade do Para- noá e diretrizes o para a expansão}

A partir do diagnóstico dimensional (análise, avaliação e programação) foram desenvolvidas 14 propostas para a área da expansão 144 hectares comportando 5.000 famílias, sem incluir o Parque dos Pinheiros. Obteve-se um bom desempenho nos projetos, principalmente aqueles que utilizaram a água como elemento norteador para o desenho urbano com parque urbano, canais de infiltração e lagoas de estocagem, compatibilizando altas densidades para melhorar a urbanidade na dimensão sociológica e baixas densidades para melhorar o ciclo da água no meio urbano.

sagísticos que caracterizam essa área como envoltório da paisagem do Conjunto Urbano Tombado.
Para demonstrar a metodologia com o resultado final dos trabalhos, escolheu-se três estudos que alcançaram melhor desempenho na disciplina e na avaliação dos próprios estudantes. Em primeiro lugar, os alunos fizeram uma análise e avaliação de desempenho da cidade do Paranoá e posteriormente geraram diretrizes para a expansão baseadas nas dimensões morfológicas dos processos de urbanização DIMPU (funcional, bioclimática, econômica, expressivo-simbólica, topoceptiva e sociológica) e nos princípios de sustentabilidade ambiental. A seguir, uma síntese do diagnóstico e o resultado dos melhores projetos.

\subsection{Os três melhores desempenhos}

\subsubsection{Projeto Grupo 1}

Mesmo considerando uma densidade de 150 hab/ha, a dimensão bioclimática foi o ponto de partida para a definição da morfologia urbana. As vias no sentido longitudinal leste-noroeste acompanham as curvas de nível. A criação de um parque urbano central e diversos núcleos de atividades (vilas urbanas) integrados às pequenas praças demonstram a preocupação com o conforto ambiental. 
Figura 3: Grupo 1 - Gabriela Nehme e Júlio Paiva
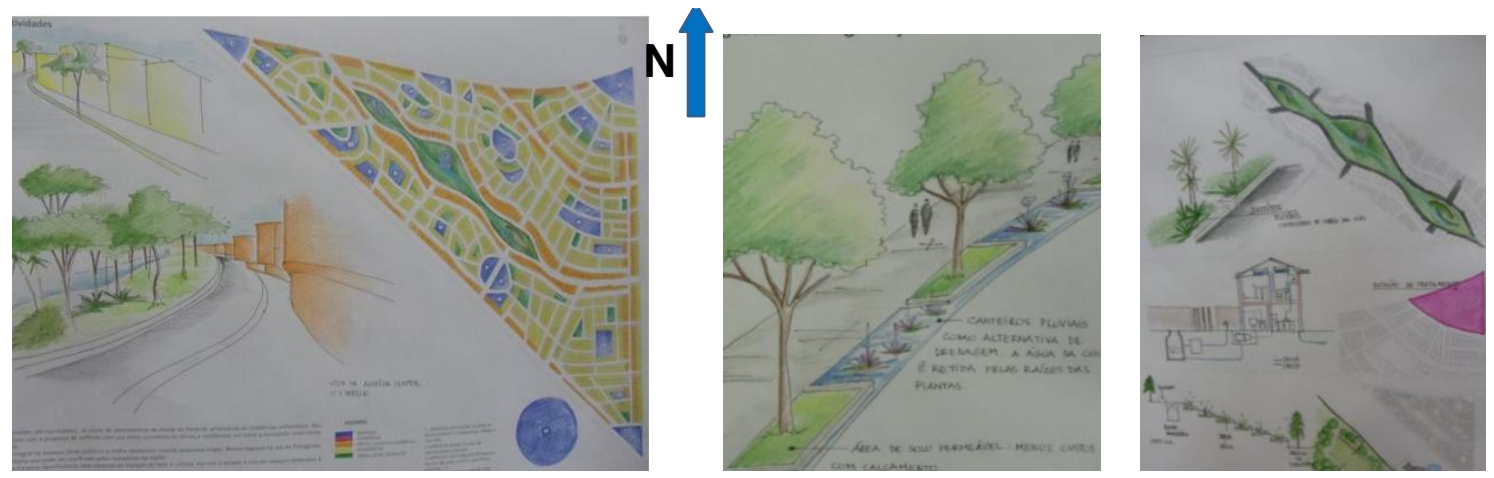

Figura 4: Grupo 2 - Camila Cardoso, Priscila Miti e Raquel Braz
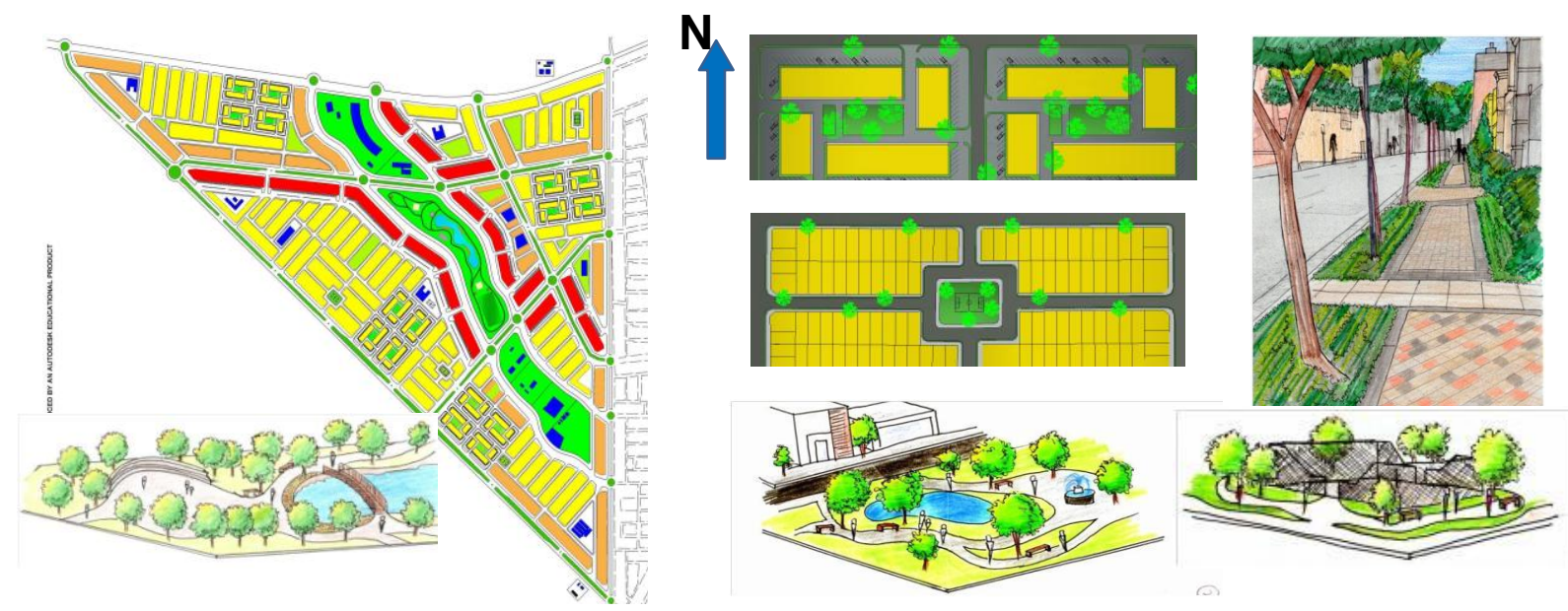

Figura 5: Grupo 3 - Ana Carolina Moreth, Louise Boeger, Nara Cunha
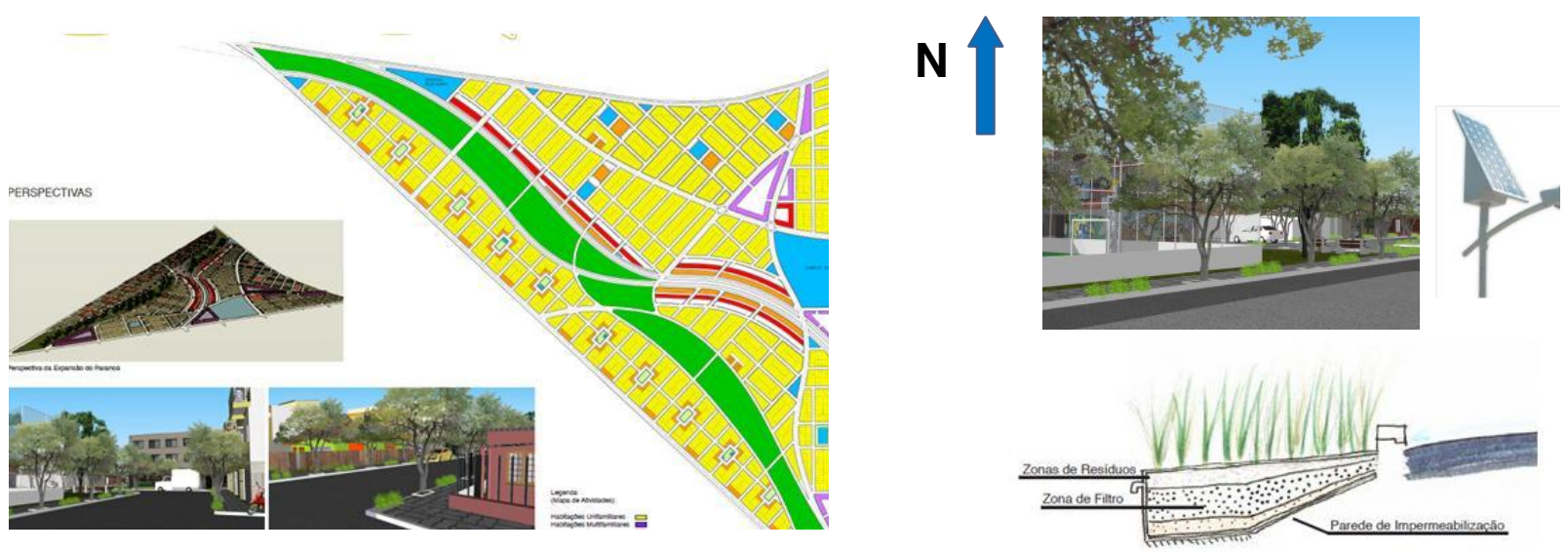

A recuperação da cobertura vegetal, os telhados verdes e os canteiros pluviais nas vias diminuem as taxas de escoamento. A malha orgânica propicia uma boa ventilação no sentido leste oeste. As águas pluviais são tratadas no próprio parque com lagoas de retenção. Os wetlands propostos tratam as águas negras na área do Parque dos Pinheiros.

\subsubsection{Projeto Grupo 2}

Aproveitando-se o sentido das curvas de nível, o traçado urbano com densidade de 150 hab/ha contém um parque linear que atravessa a cidade no sentido leste-noroeste, configurando uma área verde central, que serve como bioretenção das águas pluviais e contribui para o conforto térmico. O parque abriga uma horta comunitária para promover a saúde e o bem-estar social e gerar renda. Procurou-se localizar as macroparcelas no sentido norte sul para favorecer a orientação solar norte-sul e aproveitar a permeabilidade no sentido leste-oeste. 


\subsubsection{Projeto do Grupo 3}

Este estudo apresenta uma densidade maior em torno de 200 hab/ha. O traçado urbano é composto de dois grandes parques, um a noroeste e outro localizado próximo à Cidade do Paranoá, em ambos foram contempladas lagoas para drenagem das águas pluviais. A partir do diagnóstico do sítio físico e da infraestrutura existente, pode-se constatar a necessidade de desenvolvimento de meios alternativos para a drenagem, como lagoas de retenção das águas pluviais, que se encontram nos dois grandes parques. Na área residencial de baixa densidade encontram-se as praças menores contendo hortas comunitárias que também auxiliarão em atividades escolares devido à sua proximidade. Porém na parte superior do assentamento, a densidade proposta pode aumentar o albedo das superfícies, as ilhas de calor, caso as superfícies não sejam tratadas com vegetação nas coberturas bem como na colocação de árvores.

\section{Conclusões}

Apesar da integração transversal das disciplinas ter apresentado uma série de aspectos positivos voltados ao ensino, favorecida pelo método da DIMPU e dos princípios de sustentabilidade aplicados ao desenho urbano, algumas limitações puderam ser observadas. Nem todos os alunos encontravam-se matriculados em todas as disciplinas aqui apresentadas, principalmente porque há abertura de vagas nos turnos noturno e diurno no curso de Arquitetura e Urbanismo da FAU/UNB. Isso pode gerar um problema de integração entre as disciplinas, principalmente se uma grande parcela de alunos não está matriculada na disciplina tronco de Projeto de Urbanismo 1 do curso noturno. Fica o desafio para a coordenação do departamento de buscar soluções para equacionar a relação aluno/turno/disciplinas.

Na parte de Conforto Térmico Ambiental, como uma principal dificuldade encontrada, há um acúmulo de conteúdo na disciplina de projeto, que, exige uma conhecimento global de conforto ambiental, enquanto que os alunos de Conforto Térmico Ambiental 1 apenas lidam com a temática térmica, deixando de abordar questões fundamentais de conforto luminoso e sonoro, o que apenas será abordado em semestres subsequentes. No entanto, detectou-se como a mais rica contribuição da integração foi a sensibilidade desenvolvida pelos alunos a partir da conexão dos atributos da Dimensão Bioclimática dados em PU1 e as técnicas dadas em Conforto Térmico para perceber que os recursos ambientais disponíveis, como, por exemplo, topografia, áreas aquíferas, ventilação e radiação solar, devem ser tratados como recursos urbanísticos, permitindo que o desenho urbano gerado seja capaz de potencializar o bom desempenho do microclima local.

$\mathrm{Na}$ disciplina de Projeto Paisagístico 1 houve uma contribuição substancial de conteúdo na macrodimensão ecológica com a visão do paisagismo ecológico e da agricultura urbana, porém, os objetos de aplicação não foram os mesmos o que dificultou um pouco a transversalidade. Já na disciplina de Infraestrutura Urbana o objeto foi o mesmo para a análise, a avaliação e a programação da dimensão econômica e a macrodimensão ecológica, fato que favoreceu a assimilação do conteúdo por parte dos estudantes, porém, o professor da disciplina teve que aguardar o avanço dos estudos preliminares para orientar a parte de infraestrutura.

Em resumo, a transversalidade entre as disciplinas tem muito a evoluir, mas a motivação para dar continuidade a essa tentativa é que o conteúdo do urbanismo ecológico é comum a todas e, ao mesmo tempo, transdisciplinar, o que torna imprescindível uma conexão maior entre as disciplinas e entre os professores para promover uma educação voltada para a sustentabilidade e, assim, contribuir para a formação dos estudantes na busca por projetos urbanos mais sustentáveis.

\section{Referências Bibliográficas}

ANDRADE, Liza Maria Souza de. Agenda verde x Agenda marrom: Inexistência de princípios ecológicos para o desenho de assentamentos urbanos. Dissertação (Mestrado) PPG-FAU/ UNB, Brasília, 2005.

ANDRADE, Liza Maria Souza de, RIBAS, Otto Toledo. Desenhando com a água na Expansão do Paranoá-DF-Brasil. In: V PLURIS. Congresso para o Planejamento Regional Integrado e Sustentável. Brasília, Outubro de 2012.

CAMPOMORI.MaurícioJ.L.Atransdisciplinaridade e o ensino de projeto de arquitetura. Arquitexto Vitruvius. 048.08 04, mai 2004. Disponível em http://www.vitruvius.com.br/revistas/read/ arquitextos/04.048/588.

FONSECA Fernando Oliveira, BRAGA NETTO Pedro (2001). Parcelamentos irregulares na bacia do Lago Paranoá. In: FONSECA, 
Fernando Oliveira (org). Olhares sobre o Lago Paranoá, Brasília, p. 259 a 264.

GAUZIN-MÜLLER, Dominique. Arquiteturaecológica, 29 ejemplos europeos. Barcelona: GG, 2001.

GOUVEA, Luiz Alberto. BIOCIDADE: conceito e critérios para um desenho ambiental urbano em lugares de clima tropical de planalto. Editora Nobel, Brasília, 2002.

KOHLSDORF, Maria Elaine. Breve Histórico do Espaço Urbano como campo disciplinar. In: FARRET, Ricardo; GONZALES, Sueli; HOLANDA, Frederico de; KOHLSDORF, Maria Elaine. O espaço da cidade, contribuição à análise urbana. Projeto, Brasília 1985.

HOLANDA, Frederico de e KOHLSDORF, Gunter (1994). A arquitetura como situação relacional. Grupo de pesquisa dimensões morfológicas no processo de urbanização - PPG-FAU/UnB, Brasília.

HOLANDA, Frederico de. Arquitetura Sociológica. XII ENANPUR. INTEGRAÇÃO SULAMERICANA, FRONTEIRAS E DESENVOLVIMENTO URBANO E REGIONAL, Belém de 2007.

MEDEIROS, J.M.M. Visões de um Paisagismo Ecológico na Orla do Lago Paranoá. Dissertação de Mestrado. Brasília: UnB, 2008.

MEDEIROS, J. M. M. Novas Perspectivas para - Ensino de Paisagismo. In: 110 ENEPEA, 2012, Campo Grande - MS. ANAIS ENEPEA desafios. Campo Grande: UFMS, 2012.

ROMERO, Marta Adriana Bustos. Arquitetura do Lugar: uma visão bioclimática da sustentabilidade em Brasília, 164p. São Paulo: Editora Nova Técnica, 2011.

UNESCO (2008) - IHP. Urban Water Cycle Processes and Interactions. In: MARSALEK, Jiri, JIMÉNEZ-CISNEROS Blanca, KARAMOUZ Mohammad, MALMQUIST Per-Arne, GOLDENFUM Joel and CHOCAT Bernard. Urban Water Series. Taylor \& Francis.

\section{Agradecimentos}

Os autores agradecem aos alunos do quarto semestre do curso noturno e do sétimo semestre do curso diurno da Faculdade de Arquitetura e Urbanismo da Universidade de Brasília que cursaram as disciplinas no ano de 2012 pela contribuição e pelos desenhos disponibilizados. 